Article

\title{
Fabrication of Aliphatic Water-Soluble Polyurethane Composites with Silane Treated $\mathrm{CaCO}_{3}$
}

\author{
Eyob Wondu, Zelalem Chernet Lule and Jooheon Kim *(1) \\ School of Chemical Engineering and Materials Science, Chung-Ang University, Seoul 156-756, Korea; \\ wendueyoba@gmail.com (E.W.); zochernet@gmail.com (Z.C.L.) \\ * Correspondence: jooheonkim@cau.ac.kr; Tel.: +82-2-820-5763; Fax: +82-2-812-3495
}

Received: 3 March 2020; Accepted: 23 March 2020; Published: 29 March 2020

\begin{abstract}
In the present study, composites of water-soluble polyurethane/calcium carbonate $\left(\mathrm{CaCO}_{3}\right)$ were prepared from a soft segment of hydroxyl-terminated polybutadiene (HTPB) and polyethylene glycol (PEG, average molecular weight $=4000)$ with aliphatic diisocyanates. The functionality of $\mathrm{CaCO}_{3}$ particles was modified using aminopropyltriethoxysilane (APTES), and was confirmed by Fourier-transform infrared spectroscopy (FTIR). The solubility, hydrophilic properties, and chemical structures of the composites were analyzed by water-solubility tests, contact angle measurements, and FTIR, respectively, and the successful production of the hydrophilic water-soluble polyurethane (WSPU) structure was demonstrated. The adhesion of surface-modified $\mathrm{CaCO}_{3}$ particles to the WSPU matrix and the thermal degradation properties of the neat WSPU and $\mathrm{WSPU} / \mathrm{CaCO}_{3}$ composites were studied using field emission scanning electron microscopy (FE-SEM) and thermogravimetric analysis (TGA). The results demonstrated good adhesion of the surface-modified $\mathrm{CaCO}_{3}$ particles along with an improved thermal degradation temperature with the addition of $\mathrm{CaCO}_{3}$ particles to the WSPU matrix.
\end{abstract}

Keywords: water-soluble polyurethane; hydroxyl-terminated polybutadiene; water solubility; $\mathrm{CaCO}_{3} ;$ composites

\section{Introduction}

Polyurethane (PU) composites can be used in adhesive industries, synthetic leathers, construction industries, automotive industries, coatings, etc. In particular, water-soluble polyurethane (WSPU) is highly desired due to the need for highly flexible but tough polymers with enhanced adhesion, resistance to abrasion, and resistance to chemicals (including solvents and pollutants) [1-4]. In comparison to WSPU, conventional PU is a pollutant and is toxic to the environment $[5,6]$. Moreover, although the neat WSPU has the practical disadvantages of poor thermal, mechanical, and adhesion properties in the ambient environment [4,7-9], improvements in these properties are provided by the polymer composites.

Present-day research efforts in academia and industry alike are primarily focused on the development of environmentally benign polymer composites [8,10-14]. Hence, the development of WSPU composites by the incorporation of various fillers to enhance the thermo-mechanical and adhesion properties while causing low environmental harm and pollution is essential to the present-day research areas in PU industries. Among the various kinds of fillers, calcium carbonate $\left(\mathrm{CaCO}_{3}\right)$ is particularly attractive due to its high commercial availability, along with its ability to significantly enhance polymer properties $[1,9,10]$. WSPU/CaCO 3 composites can be applied in coating industries and automotive and adhesive industries, as $\mathrm{CaCO}_{3}$ enhances the properties of the WSPU matrix [9]. X. GaO et al. have fabricated WSPU/CaCO3 composites using polypropylene glycol as a soft segment and TDI as hard segment by treating the surface of $\mathrm{CaCO}_{3}$ with oxalic acid. They found that incorporating $\mathrm{CaCO} 3$ did not affect WSPU/CaCO3 thermal stability [9]. Although in-situ polymerization is the 
preferred method to produce polymer composites with high thermal stability, the use of $\mathrm{CaCO}_{3}$ as a filler in WSPU composites via this method is very rare. In addition, the large specific surface area of the $\mathrm{CaCO}_{3}$ particles promotes the formation of aggregates during the preparation of composites. This leads to the formation of an incompatible surface and difficulties in forming a uniform distribution of the filler in the matrix $[4,15,16]$. Therefore, the surface of the $\mathrm{CaCO}_{3}$ particles must be modified to enable their use in the formation of a uniform WSPU matrix with good surface compatibility. In present-day research in the field of composite materials, aminopropyltriethoxysilane (APTES) is a well-known surface-modifying reagent for the treatment of various fillers $[3,8,12,15,17]$.

The various raw materials used in the production of WSPUs include the diisocyanates, chain extenders, and emulsifiers, which generate the hard segments of the polymer chain, and the polyols, which constitute the soft segments. The types of diisocyanates that are available include aromatic diisocyanates, which are susceptible to UV degradation and are used where this is not a problem, and aliphatic diisocyanates, which are resistant to UV degradation and yellowing $[1,3,5,7,9,14,16-27]$. The aliphatic diisocyanates include 4, $4^{\prime}$-methylenebis(cyclohexyl isocyanate) (HMDI), isophorone diisocyanate (IPDI), tetramethyl xylene diisocyanate (TMXDI), and hexamethylene diisocyanate (HDI); the aromatic types are comprised of methylenebis(phenyl isocyanate) (MDI) and toluene diisocyanate (TDI) [28]. In addition, X. Wang. et al. reported the fabrication of graphene-reinforced WSPU composites, in which they treated the surface of graphene oxide using APTES and demonstrated that the addition of graphene oxide enhanced the WSPU's thermal stability [20].

In the present study, the aliphatic diisocyanate IPDI was selected along with dimethylolpropionic acid (DMPA) as an emulsifier and butane diol (BD) as a chain extender. Triethylamine (TEA) was used to neutralize the carboxyl group in DMPA, and the soft segment consisted of hydroxyl-terminated polybutadiene $(\mathrm{HTPB})$-polyethylene glycol $(\mathrm{PEG}$, average molecular weight $=4000)$. The presence of the same functional groups (hydroxyl groups) on both $\left.\mathrm{HTPB}[\mathrm{OH}-(\mathrm{CH} 2-\mathrm{CH}=\mathrm{CH}-\mathrm{CH} 2)-)_{n} \mathrm{OH}\right]$ and PEG [H(-O-CH2-CH2- $\left.)_{n} \mathrm{OH}\right]$ made the two soft segments compatible to each other [29]. Moreover, PEG was selected due to its hydrophilic property, while the hydrophobic HTPB was chosen to preserve the properties of the final WSPU [30]. The surface of CaCO3 was modified by APTES, and the polymer composite was fabricated via the in-situ polymerization method. Since there has not yet been any work on the HTPB-PEG-based WSPU composite, to the best of the present authors' knowledge, the present work can promote further investigations in this area.

\section{Materials and Methods}

\subsection{Materials}

Isophorone diisocyanate (IPDI, 98\%), dibutyltin dilaurate (DBTDL, 99\%), dimethylolpropionic acid (DMPA, 98\%), triethylamine (TEA, $\geq 99 \%$,), aminopropyltriethoxysilane (APTES), and 1,4-butane diol (BD, 99\%,) were obtained from Sigma-Aldrich (St. Louis, MO, USA). Polyethylene glycol 4000 (PEG4000), ethanol (>94.5\%), and tetrahydrofuran (THF, >99\%) were supplied by Dae-Jung Chemical and Metal Co. Ltd. (Seoul, Korea). Hydroxyl-terminated polybutadiene (HTPB) and calcium carbonate $\left(\mathrm{CaCO}_{3}\right.$, average size $\left.10 \mu \mathrm{m}\right)$ were kindly supplied by the South Korea Agency for Defense Development (ADD). All chemicals were used as received.

\subsection{Methods}

\subsubsection{Surface Modification of $\mathrm{CaCO}_{3}$}

The following procedures were used in modifying the surface of the $\mathrm{CaCO}_{3}$ particles. The $\mathrm{CaCO}_{3}$ particles were dried in an oven at $80{ }^{\circ} \mathrm{C}$ for about $24 \mathrm{~h}$, then subjected to surface modification for about $6 \mathrm{~h}$ at $80{ }^{\circ} \mathrm{C}$ using APTES ( $5 \mathrm{wt} . \%$ of $\left.\mathrm{CaCO}_{3}\right)$ in ethanol as a solvent. The surface-modified $\mathrm{CaCO}_{3}$ particles were then washed two times by filtration with water and dried in an oven for $24 \mathrm{~h}$. The APTES treatment of $\mathrm{CaCO}_{3}$ particles is presented in Figure 1. 


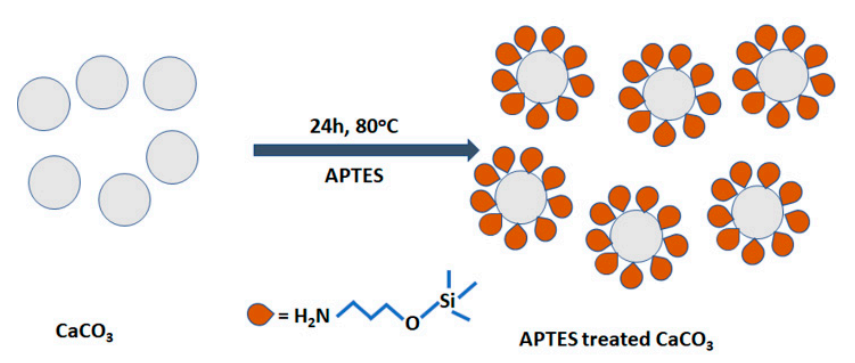

Figure 1. Scheme showing the aminopropyltriethoxysilane (APTES) treatment of calcium carbonate $\left(\mathrm{CaCO}_{3}\right)$ particles.

\subsubsection{Synthesis of Water-Soluble Polyurethane/ $\mathrm{CaCO}_{3}$ Composites}

The preparation of the water-soluble polyurethane/calcium carbonate $\left(\mathrm{WSPU} / \mathrm{CaCO}_{3}\right)$ composite was performed in a three-necked round-bottomed flask equipped with a mechanical stirrer, condenser, and dropping funnel, under a dry nitrogen atmosphere in a constant temperature oil bath. The PEG and HTPB polyols were added to THF $(30 \mathrm{~mL})$ in a 1:1 ratio and mixed with the proper amount of $\mathrm{CaCO}_{3}$ at $80{ }^{\circ} \mathrm{C}$ for $2 \mathrm{~h}$. After reducing the temperature to $60^{\circ} \mathrm{C}, 10 \mathrm{wt} . \%$ of DMPA (with respect to HTPB and PEG) was added to the reaction vessel, followed by the simultaneous addition of 1:3 HTPB:IPDI and three drops of DBTDL. The reaction was allowed to proceed for $2 \mathrm{~h}$ prior to the addition of BD as a chain extender and stirring for an additional $1 \mathrm{~h}$ at the same temperature. Finally, the temperature was reduced to $50^{\circ} \mathrm{C}$, TEA (neutralizer) was added, and the mixture was stirred for $30 \mathrm{~min}$. The chemical structures each chemical used as raw materials to produce the WSPU; the intermediates involved and the synthetic route of WSPU are presented in Figure 2. The samples were prepared with $10 \mathrm{wt} . \% \mathrm{CaCO}_{3}$ for both pristine and APTES-treated $\mathrm{CaCO}_{3}$ (WSPU/10CaCO 3 and $\mathrm{WSPU} / 10 \mathrm{TCaCO}_{3}$, respectively), and $20 \mathrm{wt} . \% \mathrm{CaCO}_{3}$ for both pristine and APTES-treated $\mathrm{CaCO}_{3}\left(\mathrm{WSPU} / 20 \mathrm{CaCO}_{3}, \mathrm{WSPU} / 20 \mathrm{TCaCO}\right.$ respectively), where T stands for APTES-treated, with respect to the weight of PEG and HTPB.

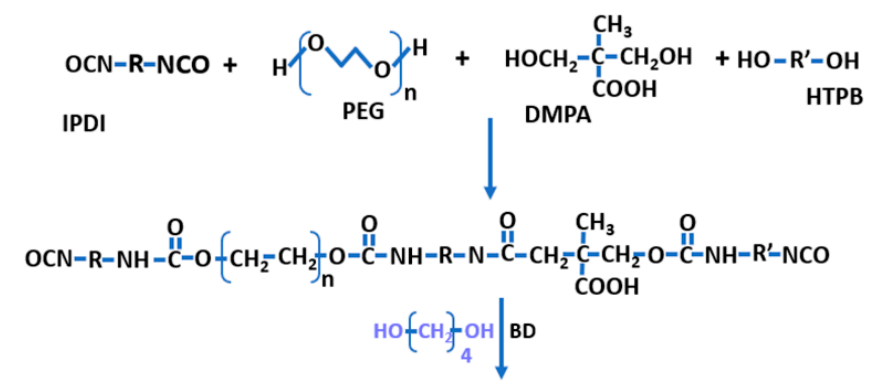

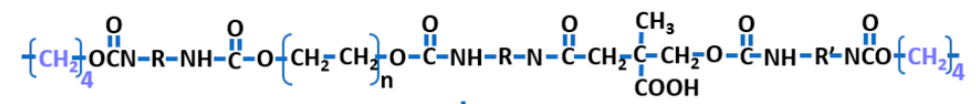

$$
\begin{aligned}
& \text { TEA } \downarrow\left(\mathrm{C}_{2} \mathrm{H}_{5}\right)_{3} \mathrm{~N}
\end{aligned}
$$<smiles>CC1CC(C)(C)C(C)(C)C1</smiles>

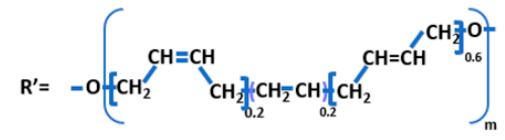

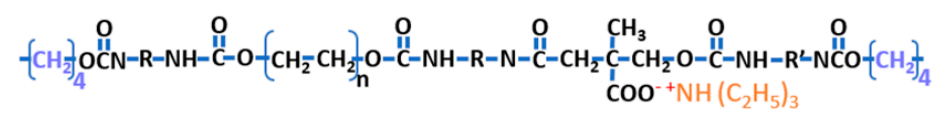

Figure 2. The structures of each chemical, the intermediates involved, and the synthetic route of water-soluble polyurethane (WSPU).

\subsection{Characterization}

The chemical structures of the WSPU and WSPU/CaCO 3 composites, and that of the $\mathrm{CaCO}_{3}$ after surface modification with APTES, were confirmed by Fourier-transform infrared spectroscopy (FT-IR; Nicolet, is5, Thermo Fisher Scientific, Seoul, Korea). For the samples of $\mathrm{CaCO}_{3}$ APTES attachment 
confirmation, FTIR specimens were prepared by utilization of potassium bromide $(\mathrm{KBr})$ background to make flakes with a 4000-650 frequency range.

The surface morphology and adhesion of the WSPU and WSPU/CaCO 3 composites were studied using field emission scanning electron microscopy (FE-SEM; Sigma, Carl Zeiss, Oberkochen, Germany) upon fracturing the specimens with liquid nitrogen and coating with platinum under a vacuum to inhibit the accumulation of charge due to the release of electrons during the analysis. FE-SEM was also used to determine the size of the $\mathrm{CaCO}_{3}$ particles and to determine whether the APTES was attached to the $\mathrm{CaCO}_{3}$ particles using energy dispersive spectroscopy (EDS).

The thermal stabilities of $5 \mathrm{mg}$ samples of the neat WSPU and WSPU/CaCO 3 were investigated by thermogravimetric analysis (TGA-2050, TA Instruments, New Castle, DE, USA). The samples were heated from 25 to $600^{\circ} \mathrm{C}$ with a heating rate of $10^{\circ} \mathrm{C} / \mathrm{min}$ in a nitrogen atmosphere.

In addition, the water-solubility test analysis was performed by pouring the $\mathrm{WSPU} / \mathrm{CaCO}_{3}$ into a vial of water and stirring for three hours at room temperature. The hydrophobic properties of the neat WSPU and the WSPU/CaCO 3 composites were analyzed at room temperature with $5 \mu \mathrm{L}$ of water by the sessile drop method using a drop shape analyzer (DSA100, KRÜSS GmbH, Hamburg, Germany). The contact angles were measured after all the samples were made flat using a hot press at $65^{\circ} \mathrm{C}$ for $20 \mathrm{~min}$, except for the neat WSPU which formed a film. The average values of the contact angles were calculated after five repeat measurements of a single specimen.

\section{Results and Discussion}

Solution process is a process of producing polymers using a solvent that can dissolve all raw materials involved in the production process. Various solvents, for instance, acetone, dichloromethane, methanol, dimethylfuran, and tetrahydrofuran, were tested for their applicability to the solution process, with the following outcomes: acetone was unable to dissolve the HTPB, dichloromethane and methanol were unable to dissolve the DMPA, dimethylfuran sparingly dissolved the DMPA, while tetrahydrofuran (THF) was finally selected for its ability to dissolve all the raw materials. The solvent was used in order to reduce the development of viscosity during polymer fabrication.

The FTIR spectra of the pristine and surface-modified $\mathrm{CaCO}_{3}$ are presented in Figure 3. The peaks at wavenumbers of 2900 and $2860 \mathrm{~cm}^{-1}$, found for both, were due to the $-\mathrm{CH}_{2}$ stretching mode, and those at around 1421 and $712 \mathrm{~cm}^{-1}$ were due to the asymmetric stretching and in plane bending of carbonates. Moreover, a wide peak due to the $-\mathrm{NH}_{2}$ (amine group) originating from APTES was observed on the APTES-treated $\mathrm{CaCO}_{3}$ spectrum at a wavenumber of $3500-3300 \mathrm{~cm}^{-1}$, thus confirming the attachment of APTES to the $\mathrm{CaCO}_{3}$ particles. In addition, the peaks around 1141 and $800 \mathrm{~cm}^{-1}$ of the APTES-treated $\mathrm{CaCO}_{3}$ corresponded to $\mathrm{Si}-\mathrm{O}-\mathrm{C}$ and $\mathrm{Si}-\mathrm{O}-\mathrm{Si}$, respectively, which indicated that the APTES was attached to the $\mathrm{CaCO}_{3}$ particles.

The morphologies of the pristine and APTES-treated $\mathrm{CaCO}_{3}$ particles was studied by using FE-SEM and EDS analysis, as shown in Figure 4. The FE-SEM results of pristine $\mathrm{CaCO}_{3}$, Figure 4 a, revealed the presence of some surface impurities, including $\mathrm{Mg}$, which appears predominantly next to $\mathrm{Ca}, \mathrm{C}$, and $\mathrm{O}$ atoms of $\mathrm{CaCO}_{3}$. The EDS analysis was performed to confirm the attachment of APTES to the $\mathrm{CaCO}_{3}$ particles. First, the chemical composition of the $\mathrm{CaCO}_{3}$ particles (Figure 4a) was confirmed by the carbon EDS mapping (Figure 4b), the oxygen EDS mapping (Figure 4c), and the calcium EDS mapping (Figure 4d). Then, the attachment of APTES to the $\mathrm{CaCO}_{3}$ (Figure 4e) was confirmed by the nitrogen EDS mapping (Figure 4f) and the silicon EDS mapping (Figure 4g). Neither nitrogen nor silicon was detected on the pristine $\mathrm{CaCO}_{3}$. 


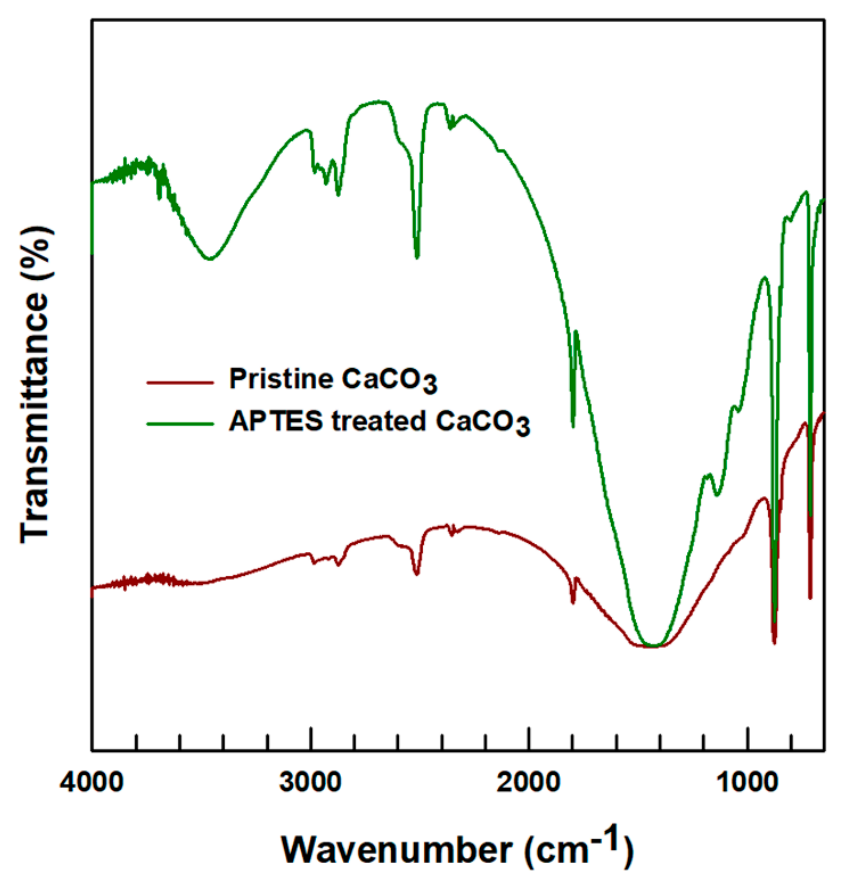

Figure 3. FTIR spectra of the pristine and APTES treated $\mathrm{CaCO}_{3}$.

(a)

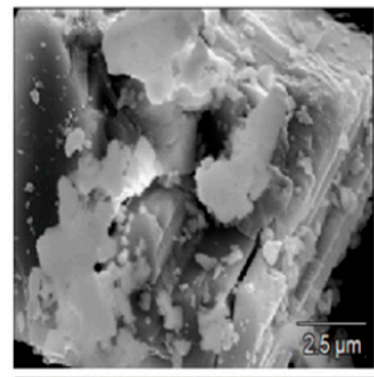

(d)

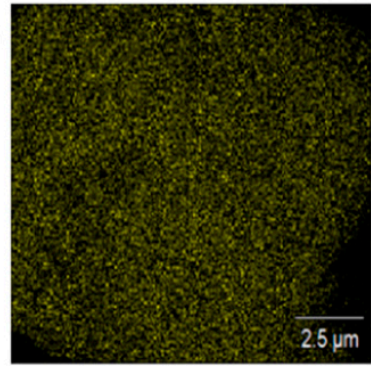

(g)

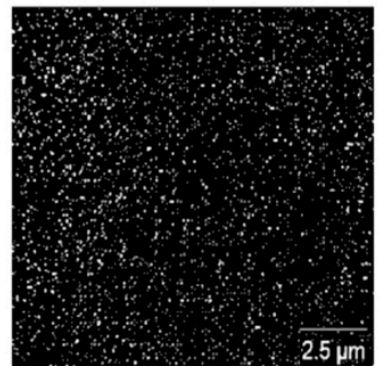

(b)

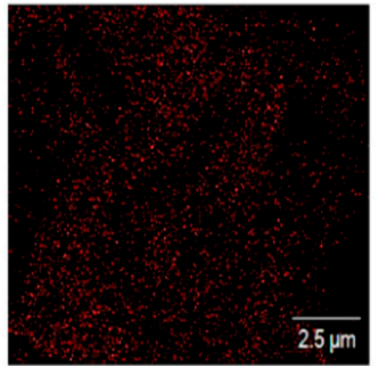

(e)

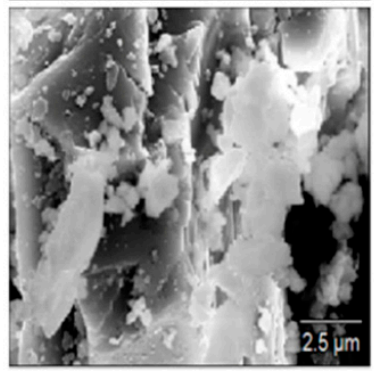

(c)

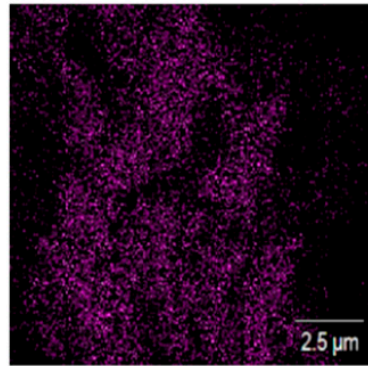

(f)

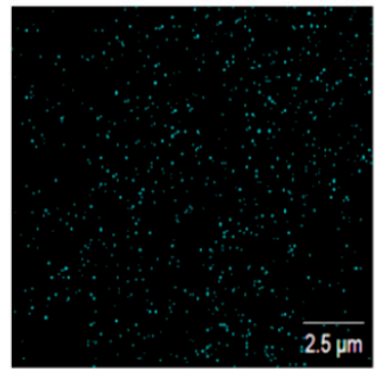

Figure 4. SEM and energy dispersive spectroscopy (EDS) analyzes of the pristine (a-d) and APTES treated (e-g) $\mathrm{CaCO}_{3}$ : (a) SEM image, (b) carbon mapping, (c) oxygen mapping, (d) calcium mapping, (e) SEM image, (f) nitrogen mapping, and (g) silicon mapping. 
The FTIR spectra of the WSPU and WSPU/CaCO 3 are presented in Figure 5. The peak at around $3250-3450 \mathrm{~cm}^{-1}$ in Figure 5a was attributed to the NH- stretching mode, thus demonstrating the appearance of the PU structure due to the urethane linkage between the polyol and diisocyanate (HTPB-PEG and IPDI). The sharp peak at around a wavenumber of $1726 \mathrm{~cm}^{-1}$ confirmed the appearance of the urethane carbonyl groups $(\mathrm{C}=\mathrm{O})$ derived from the emulsifier. This group allowed the PU to be water-soluble, which was confirmed in the water-solubility test section. The peaks at around $1311 \mathrm{~cm}^{-1}$ were due to the twisting mode of $-\mathrm{CH}_{2}$, while that at around $1360 \mathrm{~cm}^{-1}$ corresponded to the methylene groups wagging vibrations $[3,12,18]$. The peaks in the region $2800-3000 \mathrm{~cm}^{-1}$ were due to the asymmetric and symmetric stretching modes of the $-\mathrm{CH}_{2}$ groups. In the $\mathrm{WSPU} / \mathrm{CaCO}_{3}$ composites, the addition of $\mathrm{CaCO}_{3}$ to the WSPU had no significant effect on the characteristic absorbance peaks, and its influence upon the chemical structure was not visible even for composites containing $20 \%$ $\mathrm{CaCO}_{3}$.
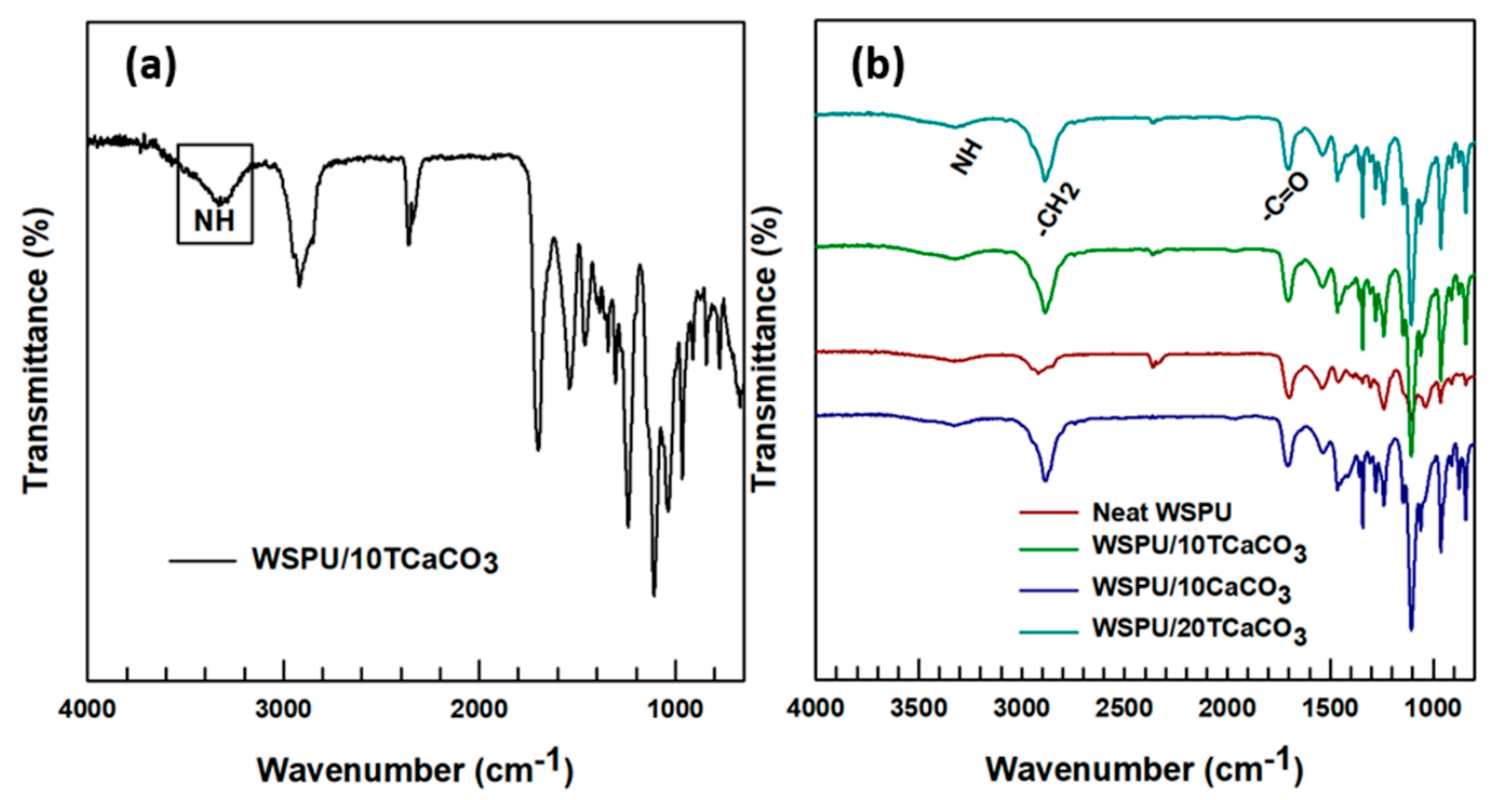

Figure 5. FTIR spectra of (a) the WSPU/ $10 \mathrm{TCaCO}_{3}$ composite; (b) the neat WSPU and various WSPU/CaCO 3 composites on the same chart.

The TGA thermograms of the neat WSPU and the WSPU/ $\mathrm{CaCO}_{3}$ composites presented in Figure 6 all revealed a closely similar appearance and decomposition pattern. The TGA analysis provided a measure of sample degradation as a function of temperature change. In Figure $6 a$, the first decomposition peak begins to appear at around $130^{\circ} \mathrm{C}$ due to the removal of moisture from the sample specimen. While the initial decomposition occurred between 130 and $230^{\circ} \mathrm{C}$, the second decomposition peak for the WSPU/CaCO 3 composites appeared at $285^{\circ} \mathrm{C}$, at which stage $25 \%$ of the composite was degraded. For the neat WSPU, the second decomposition curve extended to $300{ }^{\circ} \mathrm{C}$, at which stage $40 \%$ of the polymer was degraded. While the initial decomposition curves of both the neat WSPU and the WSPU/CaCO 3 composites were fairly similar in pattern, the second decomposition curve was distinct for the neat WSPU. In detail, the $50 \mathrm{wt} . \%$ decomposition $\left(\mathrm{D}_{1 / 2}\right)$ of the $\mathrm{WSPU} / \mathrm{CaCO}_{3}$ composite $\left(385^{\circ} \mathrm{C}\right)$ was greater than that of the neat WSPU $\left(350^{\circ} \mathrm{C}\right)$. However, the final decomposition temperature of both the neat WSPU and WSPU/CaCO 3 composites was $460{ }^{\circ} \mathrm{C}$, with no further weight loss being observed with further increase in temperature above this point. The final residues differed according to the weight percentage of $\mathrm{CaCO}_{3}$ used, such that the residue content increased with the increased weight percentage of $\mathrm{CaCO}_{3}$. However, for the final residue of $\mathrm{WSPU} / 10 \mathrm{TCaCO}_{3}$ as compared to same amount of pristine $\mathrm{CaCO}_{3}$ containing WSPU, i.e., WSPU/10CaCO 3 , the amount remaining after degradation was slightly higher, which may have been due to the surface modification that led all the $\mathrm{CaCO}_{3}$ to be attached to the matrix. 

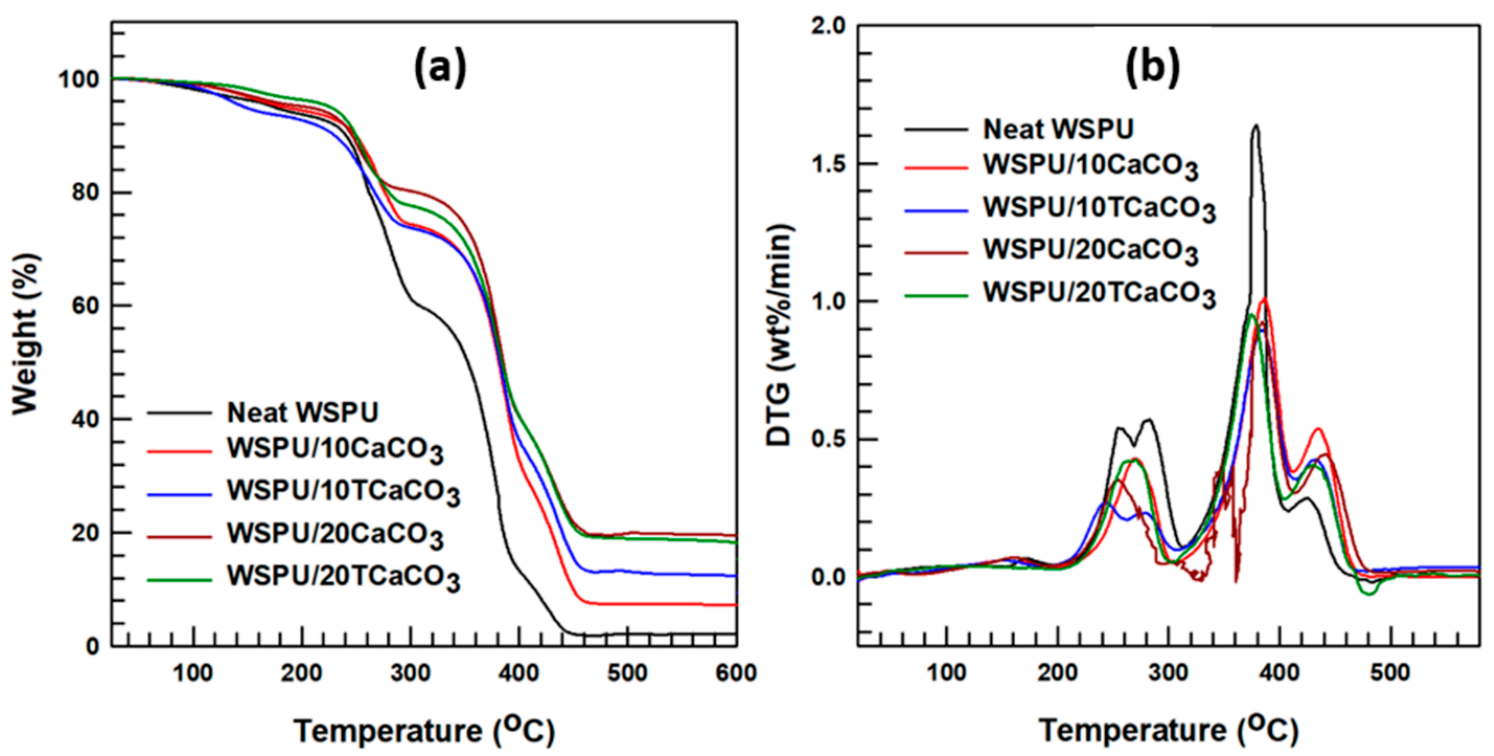

Figure 6. Thermal degradation properties of the WSPU and $\mathrm{WSPU} / \mathrm{CaCO}_{3}$ composites: (a) thermogravimetric analysis (TGA) and (b) derivative TGA (DTGA).

The derivative TGA (DTGA) plots of the neat WSPU and WSPU/CaCO 3 composites are presented in Figure $6 \mathrm{~b}$. The maximum derivative temperature of the neat WSPU was $377^{\circ} \mathrm{C}$, and that of the WSPU/CaCO 3 composite was $385^{\circ} \mathrm{C}$, which shows a slightly similar range. Figure $6 \mathrm{~b}$ of neat WSPU DTGA depicts that the height of the maximum derivative temperature was higher than the others, indicating that the thermal degradation rate of neat WSPU is higher than that of the composites. Therefore, it can be deduced that the neat WSPU degraded faster than the WSPU/CaCO 3 composites. Thus, in contrast to the work of X. GaO et al. [9], the addition of $\mathrm{CaCO}_{3}$ into the WSPU provided more thermal stability to the matrix.

The morphologies of both the WSPU and WSPU composites were examined by FE-SEM in order to investigate the distribution of the $\mathrm{CaCO}_{3}$ particles and their adherence to the WSPU. The FE-SEM images of the WSPU and WSPU/CaCO 3 composites are presented in Figure 7. Sufficiently good levels of adhesion and dispersion of the $\mathrm{CaCO}_{3}$ particles are essential for the filler to improve the final properties of the polymer composites. In Figure 7a, the nitrogen-fractured neat WSPU displays a smooth surface, while the composite (Figure $7 \mathrm{~b}, \mathrm{c}$ ) displays particles distributed over the polymer surface. Moreover, a comparison Figure $7 \mathrm{~b}, \mathrm{c}$ indicates good adherence of the surface-modified $\mathrm{CaCO}_{3}$ particles (WSPU/20TCaCO 3 , Figure 7c) whereas the high surface energy of the pristine $\mathrm{CaCO}_{3}$ particles led to their exposure on the surface of the WSPU (WSPU $/ 20 \mathrm{CaCO}_{3}$, Figure $7 \mathrm{~b}$ ) due to the lack of surface functionalization [9]. Hence, the surface treatment of the $\mathrm{CaCO}_{3}$ particles using APTES resulted in good dispersion and good adherence to the surface of the WSPU, as shown in Figure $7 \mathrm{~b}$.

The photographic images in Figure 8 present the water-solubility tests of the WSPU composites with (a) $10 \%$ and (b) $20 \% \mathrm{CaCO}_{3}$ with surface modification. In each image, the right-hand vial shows the water-solubility results of the composite, while the left-hand vial shows the water solubility of the raw composite with modified $\mathrm{CaCO}_{3}$. The composites were soluble in water within three hours of stirring at room temperature. However, the addition of $\mathrm{CaCO}_{3}$ particles did not affect the water solubility of WSPU; rather, solubility was conferred by the emulsifier (DMPA). 
(a)

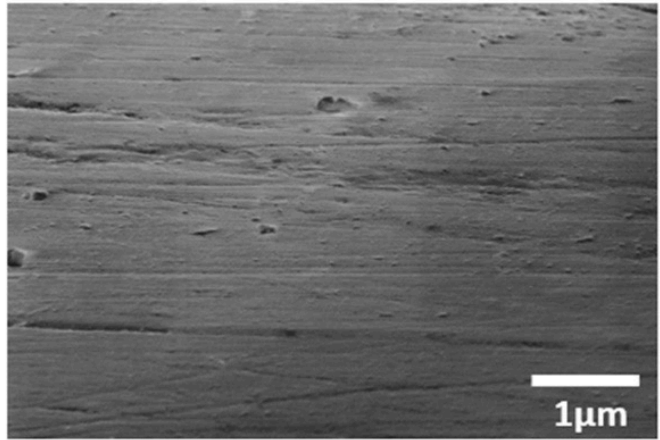

(b)

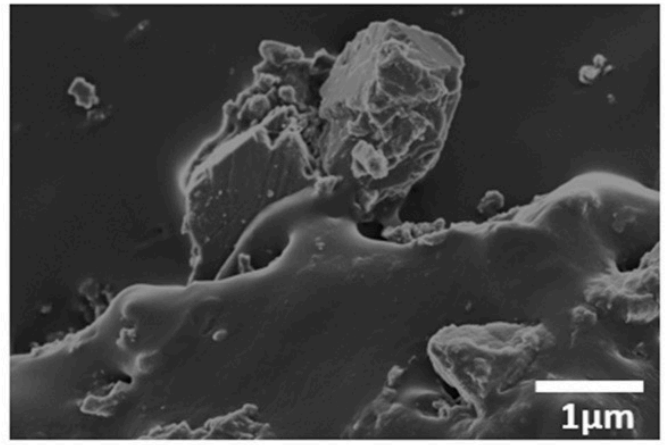

(c)

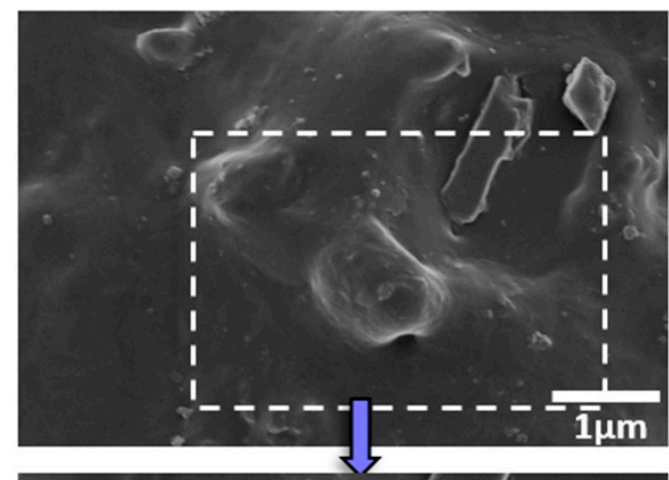

(d)

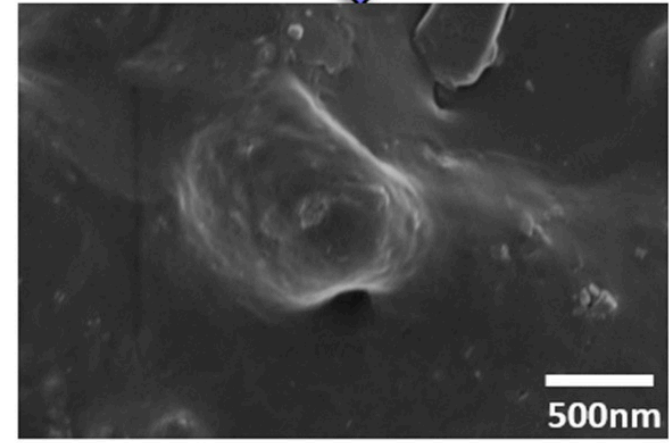

Figure 7. FE-SEM images of (a) the neat WSPU, (b) $\mathrm{WSPU} / 20 \mathrm{CaCO}_{3}$, and (c) WSPU/20TCaCO 3 ; (d) magnified image of WSPU/20TCaCO 3.
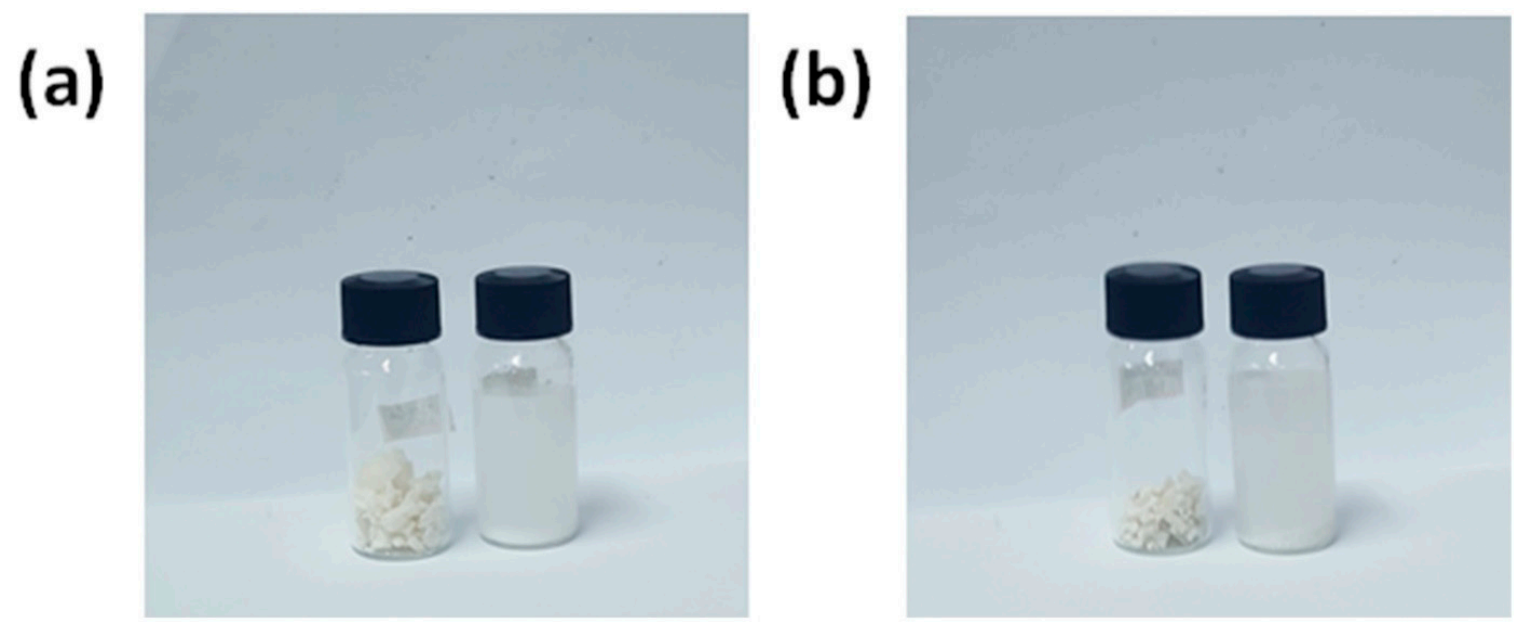

Figure 8. Water-solubility results: (a) WSPU/20CaCO 3 and (b) WSPU/20TCaCO .

The contact angle measurements of the WSPU film and the flat surface of the WSPU/CaCO composite are presented in Figure 9. Due to the application of emulsifiers, both the neat WSPU and the WSPU/CaCO 3 composites displayed hydrophilic properties and were thus water-soluble, as indicated by the above-mentioned water-solubility test. The application of $\mathrm{CaCO}_{3}$ did not affect the hydrophilic nature of the polymer, which may have been due to the immiscibility of the $\mathrm{CaCO}_{3}$ particles in water. The average contact angles were around $58^{\circ}$, thus confirming the water solubility of the composite. The images shown for neat WSPU are thicker than the composites, because it was a film that was not hot-pressed. 
(a)

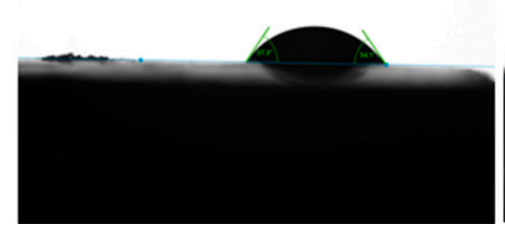

Figure 9. Contact angle WSPU/20TCaCO 3 composite. (b)
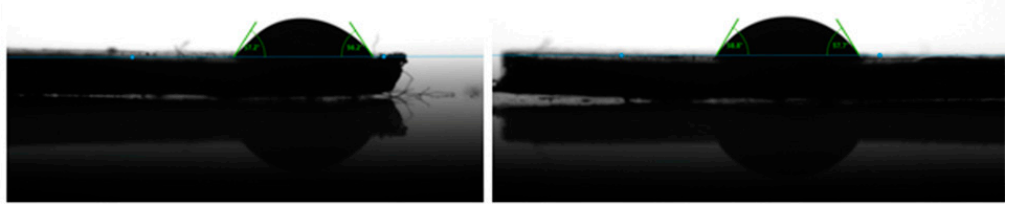

(a) neat WSPU,

(b) WSPU/10TCaCO 3 composite, and (c)

\section{Conclusions}

Water-soluble polyurethane (WSPU) composites were prepared from a soft segment of hydroxyl-terminated polybutadiene (HTPB) and polyethylene glycol (PEG, average molecular weight $=4000$ ), and a hard segment of aliphatic diisocyanate (isophorone diisocyanate, IPDI) with dimethylolpropionic acid (DMPA) as emulsifier, triethyl amine (TEA) as a neutralizer, butane diol (BD) as a chain extender, and $\mathrm{CaCO}_{3}$ particles as a filler. The water solubility and hydrophobic nature were confirmed by water-solubility tests and contact angle measurements, and the composites were water-soluble and hydrophilic, respectively. The surface of the $\mathrm{CaCO}_{3}$ particles was modified by using aminopropyltriethoxysilane (APTES), and the results of Fourier-transform infrared spectroscopy (FTIR) confirmed the successful attachment of APTES to the surface of the $\mathrm{CaCO}_{3}$ particles. The structure of the WSPU was confirmed by FTIR, which indicated the formation of urethane bonds. The distribution of the $\mathrm{CaCO}_{3}$ particles in the WSPU matrix and their adhesion to the surface were confirmed by FE-SEM, which indicated that the surface-modified $\mathrm{CaCO}_{3}$ was well-distributed and displayed good adhesion. By contrast, the pristine $\mathrm{CaCO}_{3}$ was found to form aggregates in the matrix and did not adhere to the surface. The thermal degradation properties were determined by TGA analysis, which indicated the presence of various degradation regions and the improvement in the thermal degradation properties of WSPU with the addition $\mathrm{CaCO}_{3}$.

Author Contributions: E.W.: Conceptualization, Formal analysis, Investigation, Methodology, Software, WritingOriginal draft. Z.C.L.: Data curation, Writing-Review and editing, Visualization. J.K.: Project administration, Funding acquisition, Supervision. All authors have read and agreed to the published version of the manuscript.

Funding: We gratefully acknowledge the financial support by DAPA/ADD (Defense Acquisition Program Administration/Agency for Defense Development) of Korea and the Next-Generation Converged Energy Materials Center in Yonsei University.

Conflicts of Interest: The authors declare no conflict of interest.

\section{References}

1. Wondu, E.; Oh, H.W.; Kim, J. Effect of DMPA and Molecular Weight of Polyethylene Glycol on Water-Soluble Polyurethane. Polymers 2019, 11, 1915. [CrossRef] [PubMed]

2. Lei, L.; Zhong, L.; Lin, X.; Li, Y.; Xia, Z. Synthesis and characterization of waterborne polyurethane dispersions with different chain extenders for potential application in waterborne ink. Chem. Eng. J. 2014, 253, 518-525. [CrossRef]

3. Sardon, H.; Irusta, L.; Fernández-Berridi, M.J.; Lansalot, M.; Bourgeat-Lami, E. Synthesis of room temperature self-curable waterborne hybrid polyurethanes functionalized with (3-aminopropyl)triethoxysilane (APTES). Polymer 2010, 51, 5051-5057. [CrossRef]

4. Raghu, A.V.; Lee, Y.R.; Jeong, H.M.; Shin, C.M. Preparation and physical properties of waterborne polyurethane/ functionalized graphene sheet nanocomposites. Macromol. Chem. Phys. 2008, 209, $2487-2493$. [CrossRef] 
5. Kuan, H.C.; Ma, C.C.M.; Chang, W.P.; Yuen, S.M.; Wu, H.H.; Lee, T.M. Synthesis, thermal, mechanical and rheological properties of multiwall carbon nanotube/waterborne polyurethane nanocomposite. Compos. Sci. Technol. 2005, 65, 1703-1710. [CrossRef]

6. Yang, C.H.; Yang, H.J.; Wen, T.C.; Wu, M.S.; Chang, J.S. Mixture design approaches to IPDI-H6XDI-XDI ternary diisocyanate-based waterborne polyurethanes. Polymer 1999, 40, 871-885. [CrossRef]

7. Pan, H.; Chen, D. Preparation and characterization of waterborne polyurethane/attapulgite nanocomposites. Eur. Polym. J. 2007, 43, 3766-3772. [CrossRef]

8. Cao, X.; Chang, P.R.; Huneault, M.A. Preparation and properties of plasticized starch modified with poly(E-caprolactone) based waterborne polyurethane. Carbohydr. Polym. 2008, 71, 119-125. [CrossRef]

9. Gao, X.; Zhu, Y.; Zhou, S.; Gao, W.; Wang, Z.; Zhou, B. Preparation and characterization of well-dispersed waterborne polyurethane/CaCO3 nanocomposites. Colloids Surf. A Physicochem. Eng. Asp. 2011, 377, 312-317. [CrossRef]

10. Gaudin, F.; Sintes-Zydowicz, N. Poly(urethane-urea) nanocapsules prepared by interfacial step polymerisation in miniemulsion. The droplet size: A key-factor for the molecular and thermal characteristics of the polymeric membrane of the nanocapsules? Colloids Surf. A Physicochem. Eng. Asp. 2011, 384, 698-712. [CrossRef]

11. Kausar, A. Review on Technological Significance of Photoactive, Electroactive, pH-sensitive, Water-active, and Thermoresponsive Polyurethane Materials. Polym. Plast. Technol. Eng. 2017, 56, 606-616. [CrossRef]

12. Ma, L.; Song, L.; Wang, H.; Fan, L.; Liu, B. Synthesis and characterization of poly(propylene carbonate) glycol-based waterborne polyurethane with a high solid content. Prog. Org. Coat. 2018, 122, 38-44. [CrossRef]

13. Díez-García, I.; Santamaria-Echart, A.; Eceiza, A.; Tercjak, A. Triblock copolymers containing hydrophilic PEO blocks as effective polyols for organic solvent-free waterborne poly(urethane-urea)s. React. Funct. Polym. 2018, 131, 1-11. [CrossRef]

14. Cao, X.; Dong, H.; Li, C.M. New nanocomposite materials reinforced with flax cellulose nanocrystals in waterborne polyurethane. Biomacromolecules 2007, 8, 899-904. [CrossRef]

15. Wondu, E.; Lule, Z.; Kim, J. Thermal Conductivity and Mechanical Properties of Thermoplastic Polyurethane-/Silane-Modified Al2O3 Composite Fabricated via Melt Compounding. Polymers 2019, 11, 1103. [CrossRef]

16. Kang, S.-Y.; Ji, Z.; Tseng, L.-F.; Turner, S.A.; Villanueva, D.A.; Johnson, R.; Albano, A.; Langer, R. Design and Synthesis of Waterborne Polyurethanes. Adv. Mater. 2018, 30, 1706237. [CrossRef]

17. Kuan, H.C.; Su, H.Y.; Ma, C.C.M. Synthesis and characterization of polysilicic acid nanoparticles/waterborne polyurethane nanocomposite. J. Mater. Sci. 2005, 40, 6063-6070. [CrossRef]

18. Rahman, M.M.; Zahir, H.; Kim, H. Do Synthesis and properties of waterborne polyurethane (WBPU)/modified lignin amine (MLA) adhesive: A promising adhesive material. Polymers 2016, 8, 318. [CrossRef]

19. Gu, J.; Hu, D.; Huang, J.; Huang, X.; Zhang, Q.; Jia, X.; Xi, K. One-pot synthesis and control of aqueous soluble and organic soluble carbon dots from a designable waterborne polyurethane emulsion. Nanoscale 2016, 8, 3973-3981. [CrossRef]

20. Wang, X.; Xing, W.; Song, L.; Yang, H.; Hu, Y.; Yeoh, G.H. Fabrication and characterization of graphenereinforced waterborne polyurethane nanocomposite coatings by the sol-gel method. Surf. Coat. Technol. 2012, 206, 4778-4784. [CrossRef]

21. Lee, H.T.; Lin, L.H. Waterborne polyurethane/clay nanocomposites: Novel effects of the clay and its interlayer ions on the morphology and physical and electrical properties. Macromolecules 2006, 39, 6133-6141. [CrossRef]

22. Honarkar, H. Waterborne polyurethanes: A review. J. Dispers. Sci. Technol. 2018, 39, 507-516. [CrossRef]

23. Zhou, X.; Li, Y.; Fang, C.; Li, S.; Cheng, Y.; Lei, W.; Meng, X. Recent Advances in Synthesis of Waterborne Polyurethane and Their Application in Water-based Ink: A Review. J. Mater. Sci. Technol. 2015, 31, 708-722. [CrossRef]

24. Madbouly, S.A.; Otaigbe, J.U.; Nanda, A.K.; Wicks, D.A. Rheological Behavior of Aqueous Polyurethane Dispersions: Effects of Solid Content, Degree of Neutralization, Chain Extension, and Temperature. Macromolecules 2005, 38, 4014-4023. [CrossRef]

25. Madbouly, S.A.; Otaigbe, J.U. Recent advances in synthesis, characterization and rheological properties of polyurethanes and POSS/polyurethane nanocomposites dispersions and films. Prog. Polym. Sci. 2009, 34, 1283-1332. [CrossRef]

26. Xu, D.; Wu, K.; Zhang, Q.; Hu, H.; Xi, K.; Chen, Q.; Yu, X.; Chen, J.; Jia, X. Synthesis and biocompatibility of anionic polyurethane nanoparticles coated with adsorbed chitosan. Polymer 2010, 51, 1926-1933. [CrossRef] 
27. Noble, K.-L. Progress in Organic Coatings. Prog. Org. Coat. 1997, 32, 131-136. [CrossRef]

28. Michael Szycher, P.D. Szycher's Handbook of Polyurethanes; CRC Press: Boka Raton, FL, USA, 1999 ; Volume 37.

29. Luo, Y.L.; Zhang, C.H.; Xu, F.; Chen, Y.S. Novel THTPBA/PEG-derived highly branched polyurethane scaffolds with improved mechanical property and biocompatibility. Polym. Adv. Technol. 2012, 23, 551-557. [CrossRef]

30. Luo, Y.L.; Miao, Y.; Xu, F. Synthesis, phase behavior, and simulated in vitro degradation of novel HTPB-b-PEG polyurethane copolymers. Macromol. Res. 2011, 19, 1233-1241. [CrossRef]

(C) 2020 by the authors. Licensee MDPI, Basel, Switzerland. This article is an open access article distributed under the terms and conditions of the Creative Commons Attribution (CC BY) license (http://creativecommons.org/licenses/by/4.0/). 